(C) Elsevier Scientific Publishing Company, Amsterdam - Printed in The Netherlands

BBA 47132

\title{
THE EFFECT OF MAGNESIUM IONS ON ACTION SPECTRA FOR RE- ACTIONS MEDIATED BY PHOTOSYSTEMS I AND II IN SPINACH CHLO- ROPLASTS
}

\section{ECKHARD LOOS}

Fachbereich Biologie der Universität, 84 Regensburg, Universitätsstr. 3l (G.F.R.)

(Received December 22nd, 1975)

\section{SUMMARY}

Action spectra were measured for positive changes in variable fluorescence (emission $>665 \mathrm{~nm}$ ) excited by a beam of $485 \mathrm{~nm}$ chopped at $75 \mathrm{~Hz}$. The action of two further beams was compared, one being variable, the other (reference) constant with respect to wavelength and intensity. Comparison was achieved by alternating the reference and the variable wavelength beams at $0.3 \mathrm{~Hz}$ and adjusting the intensity of the latter such as to cancel out any $0.3 \mathrm{~Hz}$ component in the $75 \mathrm{~Hz}$ fluorescence signal. The relative action then was obtained as the reciprocal of the intensity of the variable wavelength beam. Similarly, action spectra were measured for $\mathrm{O}_{2}$ evolution with ferricyanide/ $p$-phenylenediamine as electron acceptor, and for $\mathrm{O}_{2}$ uptake mediated by methyl viologen with ascorbate 3-( $p$-chlorophenyl)-1,1-dimethylurea as electron donor in the presence of 2,6-dichlorophenolindophenol.

Addition of $5 \mathrm{mM} \mathrm{MgCl}$ increases the relative action around $480 \mathrm{~nm}$ for the change in variable fluorescence and $p$-phenylenediamine-dependent $\mathrm{O}_{2}$ evolution, and decreases it for methyl viologen-mediated $\mathrm{O}_{2}$ uptake with 2,6-dichlorophenolindophenol/ascorbate as electron donor in the presence of 3-( $p$-chlorophenyl)-1,1-dimethylurea. The change in variable fluorescence and $\mathrm{O}_{2}$ evolution are stimulated by $\mathrm{MgCl}_{2}$, whereas $\mathrm{O}_{2}$ uptake is inhibited by it.

The results are discussed in terms of a model assuming a tripartite organization. of the photosynthetic pigments (Thornber, J. P. and Highkin, H. R. (1974) Eur. J. Biochem. 41, 109-116; Butler, W. L. and Kitajima, M. (1975) Biochim. Biophys. Acta $396,72-85) . \mathrm{MgCl}_{2}$ is thought to promote energy transfer to Photosystem II from a light-harvesting pigment complex serving both photosystems.

\section{INTRODUCTION}

Effects of $\mathrm{Mg}^{2+}$ on energy transfer between the two photoreactions have been deduced from the action of this ion on fluorescence and Hill reactions [1-3]. By

Abbreviations: DCIP, 2,6-dichlorophenolindophenol; CMU, 3-(p-chlorophenyl)-1,1-dimethylurea; DCMU, 3-(3,4-dichlorophenyl)-1,1-dimethylurea; $F_{\mathrm{v}}$, fluorescence of variable yield. 

several authors, $\mathrm{Mg}^{2+}$ and other divalent cations have been found to stimulate System II-dependent phenomena, for instance to increase the variable fluorescence $\left(F_{v}\right)[4,5]$, the peak ratio of the $685 \mathrm{~nm} / 735 \mathrm{~nm}$ fluorescence emission [1] and to accelerate the Hill reaction with DCIP or ferricyanide as electron acceptor $[1,2,6]$; on the other hand, the reduction of NADP or methyl viologen with an artificial electron donor system in the presence of DCMU, a reaction driven by System I, was inhibited by $\mathrm{Mg}^{2+}[1,2]$. To explain these observations, the hypothesis has been proposed [1] that $\mathrm{Mg}^{2+}$ is interrupting a spill-over of energy from Photosystem II into Photosystem I, thus keeping more of the light energy in Photosystem II. Alternatively, the action of $\mathrm{Mg}^{2+}$ has been discussed in terms of a promotion of energy flow from System I into System II [3]; an energy transfer in this direction has recently been claimed to occur in chloroplasts from Euglena [7]. To decide between these two hypotheses, an experimental approach was chosen which has been similarly followed by Vernotte and coworkers [8]: when action spectra are measured with and without $\mathrm{Mg}^{2+}$ for reactions mediated by Photosystem I or Photosystem II, a change in the shape of one of the spectra should indicate an energy transfer from the other, differently absorbing photosystem; this in turn serving as an energy donor, should show no change due to $\mathrm{Mg}^{2+}$ in the wavelength dependence of its respective reaction. According to these considerations action spectra in the presence and absence of $\mathrm{Mg}^{2+}$ were determined for changes in $F_{\mathrm{v}}\left(\Delta F_{\mathrm{v}}\right)$ and for $p$-phenylenediamine reduction, both being System II-sensitized reactions [9-11]; further, for methyl viologen-mediated $\mathrm{O}_{2}$ uptake in the presence of an artificial electron donor plus CMU, a reaction used to measure System I activity [2, 8]. The results presented in this work are not consisten with either of the two models but support the recently emerged concept of a tripartite organization of the photosynthetic pigments $[12,13]$.

\section{MATERIALS AND METHODS}

Spinach was grown in the green-house; for isolation of chloroplasts $30 \mathrm{~g}$ of washed, cooled leaves were homogenized for $4 \mathrm{~s}$ in $120 \mathrm{ml}$ of a medium containing $0.4 \mathrm{M}$ sucrose, $10 \mathrm{mM} \mathrm{KCl}, 1 \mathrm{mM} \mathrm{MgCl} 2,0.5 \mathrm{mM}$ EDTA, $3.5 \mathrm{mM} \mathrm{Na}_{4} \mathrm{P}_{2} \mathrm{O}_{7}$ and $20 \mathrm{mM}$ Tricine $/ \mathrm{KOH}$ (pH 8.0). The slurry was filtered through two layers of thick cotton cloth and chloroplasts were collected from the green juice by centrifugation at $4000 \times g$ for $40 \mathrm{~s}$. The pellet was washed with a medium containing $0.4 \mathrm{M}$ sucrose, $10 \mathrm{mM} \mathrm{KCl}, 20 \mathrm{mM}$ Tricine $/ \mathrm{KOH}(\mathrm{pH} 8.0)$ and finally resuspended in the basic medium of $10 \mathrm{mM} \mathrm{KCl}, 20 \mathrm{mM}$ Tricine $/ \mathrm{KOH}$ (pH 8.0) to yield a stock suspension of $250 \mu \mathrm{g}$ chlorophyll $/ \mathrm{ml}$.

Changes in $F_{\mathrm{v}}$ were measured as the increase in fluorescence yield of a chopped $485 \mathrm{~nm}$ light beam $(75 \mathrm{~Hz})$ when light of other frequency was added; this corresponds to a reduction of the quencher Q [9]. Since only the action of Photosystem II in reducing $\mathrm{Q}$ should be measured, $\mathrm{CMU}$ was included in the reaction mixture to prevent an oxidation of Q by Photosystem I (cf. ref. 9). However, Q was reoxidized otherwise, probably by oxygen, upon shutting off the additional light. This made it possible to obtain action spectra for $\Delta F_{\mathrm{v}}$ in the following way (Fig. 1): additional light of constant intensity is chopped at $0.3 \mathrm{~Hz}$, producing in the $75 \mathrm{~Hz}$ fluorescence signal a $0.3 \mathrm{~Hz}$ modulation representing $\Delta F_{\mathrm{v}}$. This modulation is compensated by adjusting the intensity of an alternating beam of variable wavelength; the relative action then is given 


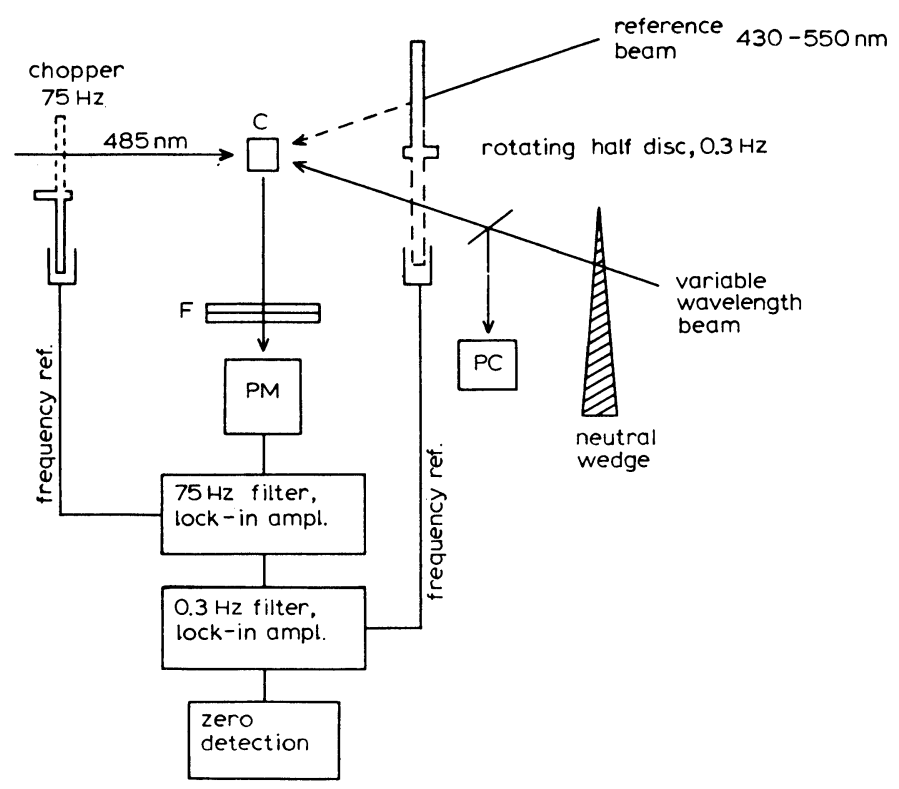

Fig. 1. Diagram of set-up for measuring action spectra for $\Delta F_{\mathrm{v}} . \mathrm{C}$, sample cuvette of 1 by $1 \mathrm{~cm}$ cross section; F, blocking filters Filtraflex DT (Balzers) and RG 665, $6 \mathrm{~mm}$ (Schott); PM, photomultiplier (Hamamatsu R 374); PC, calibrated vacuum photocell (Hamamatsu R 310).

by the inverse of the intensity of the variable wavelength beam. The sensitivity of the method depends mainly on the size of the signal caused by any single $0.3 \mathrm{~Hz}$ beam and on the noise at the output of the $0.3 \mathrm{~Hz}$ lock-in amplifier (cf. ref. 14). Under the conditions used here the relative actions for $\Delta F_{\mathrm{v}}$ were measured with an accuracy of approx. $\pm 2 \%$. Measurements within the course of an experiment were reproducible within the same limits. The method provides action spectra under steady-state conditions and eliminates errors due to aging of the chloroplasts or to eventual non-linear intensity vs. rate characteristics (cf. ref. 14). The beam chopped at $75 \mathrm{~Hz}$ and the one of variable wavelength were obtained from two $500-\mathrm{mm}$ grating monochromators (Bausch and Lomb) with slits set for $6 \mathrm{~nm}$ half-band width and with filters KIF 560 and BG 38 (both Schott), respectively, to cut down stray light. The reference beam presented a broad blue band defined by filters BG 23 plus BG 28 (Schott). The intensity of the variable wavelength beam (unchopped) was relatively low, e.g. $100 \mathrm{ergs} / \mathrm{cm}^{2}$ per s at $485 \mathrm{~nm}$, which fell in a range of a linear relationship between light intensity and $\Delta F_{\mathrm{v}}$. The time-averaged intensity of the $75 \mathrm{~Hz}, 485 \mathrm{~nm}$ beam was $280 \mathrm{ergs} / \mathrm{cm}^{2}$ per s. This intensity proved to be saturating for $\Delta F_{\mathrm{v}}$ when the intensity of the $75 \mathrm{~Hz}$ beam was varied and $\Delta F_{\mathrm{v}}$ was caused by only one $0.3 \mathrm{~Hz}$ beam. Absorption spectra were measured using the variable wavelength beam with the photomultiplier $3.5 \mathrm{~cm}$ behind the cuvette. An opal glass was inserted between them, as well as a KIF 560 filter (Schott) to cut off fluorescence.

Relative rates of $\mathrm{O}_{2}$ uptake or $\mathrm{O}_{2}$ evolution were measured with a rate electrode similar to that described by Pickett and French [15]. Action spectra were obtained analogous to those for $\Delta F_{v}$ by matching the reference beam with the variable wavelength beam. At the light intensities to be used, there was a linear relationship between 
intensity and $\mathrm{O}_{2}$ evolution, whereas with the $\mathrm{O}_{2}$ uptake reaction a non-linearity occurred, indicating beginning light saturation; action spectra for $\mathrm{O}_{2}$ uptake were measured at rates which on a light vs. intensity curve were $10-30 \%$ below linearity.

\section{RESULTS}

\section{Action spectra for changes in variable fluorescence $\left(\Delta F_{\mathrm{v}}\right)$}

In Fig. $2 \mathrm{~A}$ are shown action spectra for $\Delta F_{\mathrm{v}}$ in the presence and absence of $\mathrm{Mg}^{2+}$. The ion caused approx. a 5-fold increase of $\Delta F_{\mathrm{v}}$; for better comparison, therefore, the spectra have been normalized at $435 \mathrm{~nm}$. With $\mathrm{Mg}^{2+}$, a relatively stronger contribution of pigments absorbing around $480 \mathrm{~nm}$, obviously chlorophyll $b$ and/or carotenoids, is seen. The ratio $+\mathrm{Mg}^{2+} /-\mathrm{Mg}^{2+}$ of the peaks at $475 \mathrm{~nm}$ is 1.17 in Fig. 2A; in three other sets of spectra with different chloroplast preparations, it varied between 1.11 and 1.21. There is a flattening effect of $\mathrm{Mg}^{2+}$ on absorption spectra of chloroplasts [16]; to exclude the possibility that the difference in the action spectra was due to such an effect, absorption spectra were measured with precautions taken to avoid distortions from scattering (see Materials and Methods). $\mathrm{Mg}^{2+}$ causes a weak flattening (Fig. 2B); the difference in absorption, however, cannot account for the difference between the action spectra, neither in size nor in its wavelength dependence (Fig. 2, bottom). A comparison of Figs. 2A and 2B shows further a relatively high efficiency of chlorophyll $b$ and/or carotenoids, in sensitizing $\Delta F_{\mathrm{v}}$ even without $\mathrm{Mg}^{2+}$. The same has previously been observed [17], probably with regard to steady-state fluorescence. Variable and steady-state fluorescence seem to emanate mainly from the same pigment system $[9,10]$. Action spectra for steady-state fluorescence in fact svere affected by $\mathrm{Mg}^{2+}$ similarly to those for $\Delta F_{\mathrm{v}}$, though to a somewhat less pronounced degree (unpublished results).

The hypothesis of $\mathrm{Mg}^{2+}$ suppressing spill-over from Photosystem II to Photosystem $I$ is not supported by the results obtained, since the shape of the action spec-

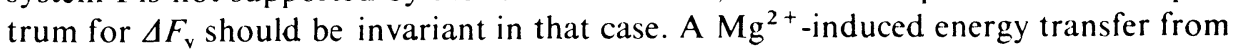

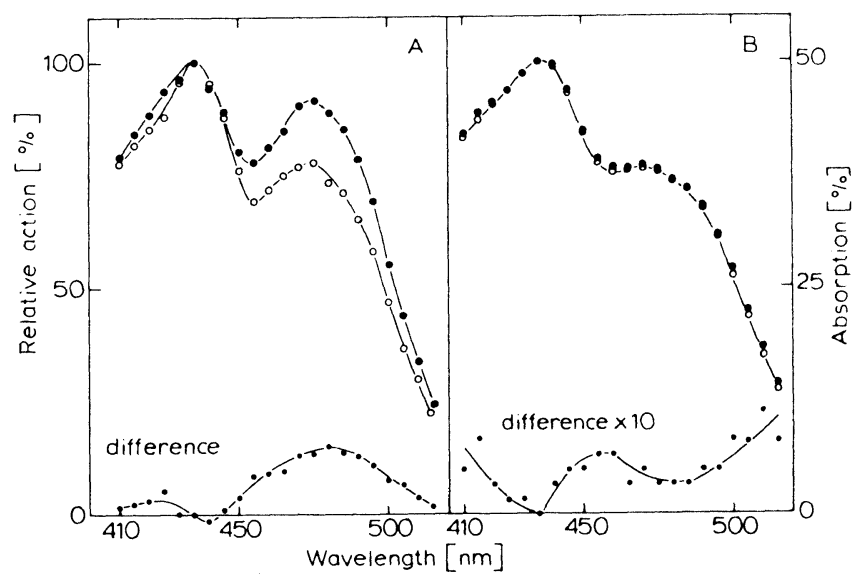

Fig. 2. Action spectra for $A F_{\mathrm{v}}(\mathrm{A})$ and absorption spectra (B) in the absence (circles) and presence (dots) of $5 \mathrm{mM} \mathrm{MgCl}$. The basic medium contained $5 \mu \mathrm{g} \mathrm{chlorophyll/ml} \mathrm{and} 15 \mu \mathrm{M} \mathrm{CMU}$. 
Photosystem I to Photosystem II does not seem plausible either, since the pigments brought into action by the ion have a relatively high chlorophyll $b$ and/or carotenoid content, a property which is not only exhibited by Photosystem I [18].

Action spectra for $\mathrm{O}_{2}$ evolution with p-phenylenediamine as electron acceptor

Reduction of $p$-phenylenediamine is supposed to be driven by Photosystem II [11]; it was followed here by detecting $\mathrm{O}_{2}$ evolution. Action spectra for this reaction were measured in addition to those for $\Delta F_{v}$ in order to substantiate the expectation of $\mathrm{Mg}^{2+}$ acting equally on the spectral dependence of all reactions sensitized by Photosystem II. The rate of $\mathrm{O}_{2}$ evolution was increased by $\mathrm{Mg}^{2+}$ (Table I); this agrees with observations of others [19], especially on the analogous DCIP reduction [1, 2].

\section{TABLE I}

RELATIVE RATES OF $\mathrm{O}_{2}$ EVOLUTION AND $\mathrm{O}_{2}$ UPTAKE IN THE PRESENCE AND ABSENCE OF $\mathrm{Mg}^{2+}$

For $\mathrm{O}_{2}$ evolution the basic medium in the flow system contained $0.15 \mathrm{mM}$ ferricyanide and $50 \mu \mathrm{M}$ p-phenylenediamine; for $\mathrm{O}_{2}$ uptake the additions were instead $5 \mu \mathrm{M}$ DCIP, $2 \mathrm{mM}$ ascorbate, $15 \mu \mathrm{M}$ CMU, $1 \mu \mathrm{M}$ methyl viologen and $1 \mathrm{mM} \mathrm{NaN}_{3}$. The concentration of $\mathrm{MgCl}_{2}$ was $5 \mathrm{mM}$ if present. Exposures of $1 \mathrm{~min}$ were given with light of $410 \mathrm{~nm}$ as used for action spectra.

\begin{tabular}{lcll}
\hline Experiment & $-\mathrm{Mg}^{2+}$ & $+\mathrm{Mg}^{2+}$ & $+\mathrm{Mg}^{2+} /-\mathrm{Mg}^{2+}$ \\
\hline $\mathrm{O}_{2}$ evolution (relative) & & \\
1 & 30 & 47 & 1.56 \\
2 & 28 & 42 & 1.50 \\
$\mathrm{O}_{2}$ & uptake (relative) & & \\
3 & 360 & 270 & 0.75 \\
4 & 255 & 112 & 0.44 \\
\hline
\end{tabular}

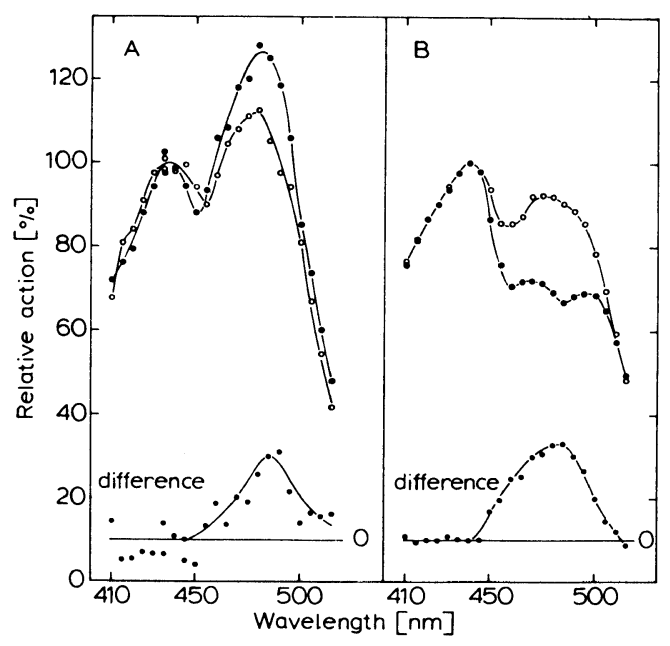

Fig. 3. Action spectra for $\mathrm{O}_{2}$ evolution (A) and $\mathrm{O}_{2}$ uptake (B) in the absence (circles) and presence (dots) of $5 \mathrm{mM} \mathrm{MgCl}$. The reaction mixtures used are given in the legend to Table I. 
An example of the action spectra obtained is depicted in Fig. 3A. Clearly, $\mathrm{Mg}^{2+}$ promotes the efficiency in the region around $480 \mathrm{~nm}$, as was the case with $\Delta F_{\mathrm{v}}$. The ratio $+\mathrm{Mg}^{2+} /-\mathrm{Mg}^{2+}$ of the peaks at $480 \mathrm{~nm}$, which is 1.12 in Fig. 3A, was 1.09 in another experiment; with chloroplasts from field-grown spinach, it was as high as 1.65. The spectra are, in shape, different from those for $\Delta F_{v}$, e.g. the ratio of the $480 \mathrm{~nm} /$ $435 \mathrm{~nm}$ peaks is higher; this may be caused by enhanced mutual shading in the denser chloroplast suspension required for the $\mathrm{O}_{2}$ measurements (cf. ref. 20). Since, however, the effect of $\mathrm{Mg}^{2+}$ is qualitatively the same, identical conclusions are drawn as from the spectra for $\Delta F_{\mathrm{v}}$.

\section{Action spectra for $\mathrm{O}_{2}$ uptake mediated by System I}

To obtain action spectra for a System I-dependent reaction, $\mathrm{O}_{2}$ uptake was measured with an artificial electron donor system in the presence of CMU to block electron transport from System II. The effect of $\mathrm{Mg}^{2+}$ on the rate of this reaction was to slow it down (Table I) which generally is in line with the literature [2, 21]; (however, see ref. 19). Action spectra in the presence and absence of $\mathrm{Mg}^{2+}$ are presented in Fig. 3B. In contrast to the spectra for System II activity (Figs. 2A and 3A) a diminished action of blue-green light is seen in the presence of $\mathrm{Mg}^{2+}$; this is in accordance with a lowered action of chlorophyll $b$ for System I-mediated $\mathrm{O}_{2}$ uptake in the red wavelength range [8]. Chlorophyll $b$ seems to be more affected than carotenoids, since with $\mathrm{Mg}^{2+}$ a carotenoid peak emerges which otherwise is hidden in the chlorophyli $b$ action. The difference spectrum $\left(-\mathrm{Mg}^{2+}\right)-\left(+\mathrm{Mg}^{2+}\right)$ peaks around $480 \mathrm{~nm}$, as does the corresponding spectrum $\left(+\mathrm{Mg}^{2+}\right)-\left(-\mathrm{Mg}^{2+}\right)$ for $p$-phenylenediamine reduction (Fig. 3, bottom). The spectra for $\mathrm{O}_{2}$ uptake are more precise, due to the relatively larger rates of $\mathrm{O}_{2}$ exchange available for measurements (cf. Table I). With three different chloroplast preparations the ratio $+\mathrm{Mg}^{2+} /-\mathrm{Mg}^{2+}$ of action at $480 \mathrm{~nm}$ was $0.71,0.72$ and 0.78 .

The decrease of $\mathrm{O}_{2}$ uptake rates by $\mathrm{Mg}^{2+}$ with a concomitant loss in chlorophyll $b$ action would suggest an interruption of energy transfer from Photosystem II to Photosystem I, a conclusion reached previously on the basis of action spectra work [8]. This, however, cannot be reconciled with other results of this study (see above).

\section{DISCUSSION}

The hypothesis of $\mathrm{Mg}^{2+}$ suppressing spill-over from Photosystem II to Photosystem $I$ is consistent with the observed increase in Photosystem II activity $\left(\Delta F_{\mathrm{v}}\right.$ and $p$-phenylenediamine-dependent $\mathrm{O}_{2}$ evolution). The spectral dependence, however, of a Photosystem II-driven reaction should not be influenced by such a regulation, since the pigment composition of Photosystem II should not be altered by $\mathrm{Mg}^{2+}$. The $\mathrm{Mg}^{2+}$-induced changes of the action spectra for Photosystem II-sensitized reactions (Figs. 2A and 3A), therefore, do not support the above hypothesis. By analogous reasoning, a control of spill-over from Photosystem I to Photosystem II is not compatible with a changing wavelength dependency of a reaction mediated by Photosystem I (Fig. 3A). Instead, the phenomena can be explained satisfactorily in the framework of a tripartite organization of the photosynthetic apparatus as put forward recently $[12,13]$. According to this model, a light-harvesting pigment protein complex 
is able to transfer light energy into the two photosystems proper. This antenna pigment complex is supposed to have a relatively high chlorophyll $b$ content, whereas less chlorophyll $b$ is ascribed to Photosystem II and essentially none of this pigment to Photosystem I. If it is realized that Photosystem II-driven reactions are generally increased and Photosystem I-mediated ones inhibited by $\mathrm{Mg}^{2+}$ (Table I; refs. 1, 2 and 6), and this is correlated with the appearance, or disappearance, respectively, of chlorophyll $b$ action (Figs. 2A and 3), the following seems to be plausible: the energy transfer from the antenna pigment complex into both photosystems is shifted by $\mathrm{Mg}^{2+}$ such as to feed a greater portion into Photosystem II, a gain for Photosystem II which is a loss for Photosystem $\mathbf{I}$.

There are relatively smaller changes caused by $\mathrm{Mg}^{2+}$ in the action spectrum for $p$-phenylenediamine reduction than in that for $\mathrm{O}_{2}$ uptake, e.g. the percentual changes are $+9 \%$ and $-28 \%$, respectively, at $480 \mathrm{~nm}$ (Fig. 3). This would suggest for the absorption spectra a greater similarity of the light-harvesting complex with Photosystem II than with Photosystem I. This agrees with the above model which predicts the greater similarity between the chlorophyll $b$-rich light-harvesting complex and Photosystem II to be due to the occurrence of chlorophyll $b$ in Photosystem II and lack of it in Photosystem I.

It is difficult to give a quantitative estimate of the $\mathrm{Mg}^{2+}$-induced shift of energy transfer. One would have to consider secondary effects of $\mathrm{Mg}^{2+}$ on reaction rates [8] and would have to make assumptions, e.g. on the efficiency of energy transfer into Photosystems I and II. Another challenging problem would be to demonstrate that $\mathrm{Mg}^{2+}$ affects energy transfer also in vivo, and if so, how it comes into action.

\section{ACKNOWLEDGEMENTS}

Thanks are due to Dr. W. Tanner for discussions and to Dipl.-Ing. D. Weymann for construction of the lock-in amplifiers. This work was supported by the Deutsche Forschungsgemeinschaft.

\section{REFERENCES}

1 Murata, N. (1969) Biochim. Biophys. Acta 189, 171-181

2 Briantais, J.-M., Vernotte, C. and Moya, J. (1973) Biochim. Biophys. Acta 325, 530-538

3 Sun, A. and Sauer, K. (1972) Biochim. Biophys. Acta 256, 409-427

4 Homann, P. (1969) Plant Physiol. 44, 932-936

5 Mohanty, P., Braun, B. Z. and Govindjee (1973) Biochim. Biophys. Acta 292, 459-476

6 Li, Y.-S. (1975) Biochim. Biophys. Acta 376, 180-188

7 Jennings, R. C. and Forti, G. (1974) Biochim. Biophys. Acta 376, 89-96

8 Vernotte, C., Briantais, J.-M. and Bennoun, P. (1973) C. R. Acad. Sci. Paris, T. 277, Sér. D, 1695-1698

9 Duysens, L. N. M. and Sweers, H. E. (1963) in Studies on Microalgae and Photosynthetic Bacteria (Ashida, J., ed.), pp. 353-372, University of Tokyo Press, Tokyo

10 Lavorel, J. (1964) Biochim. Biophys. Acta 88, 20-36

11 Ouitrakul, R. and Izawa, S. (1973) Biochim. Biophys. Acta 305, 105-118

12 Thornber, J. P. and Highkin, H. R. (1974) Eur. J. Biochem. 41, 109-116

13 Butler, W. L. and Kitajima, M. (1975) Biochim. Biophys. Acta 396, 72-85

14 Loos, E. (1974) in Proceedings of the Third International Congress on Photosynthesis (Avron, M., ed.), pp. 997-1000, Elsevier Scientific Publishing Co., Amsterdam

15 Pickett, J. M. and French, C. S. (1967) Proc. Natl. Acad. Sci. U.S. 57, 1587-1593 
16 Krause, G. H. (1974) in Membrane Transport in Plants (Zimmermann, U. and Dainty, J., ed.), pp. 274-280, Springer Verlag, Berlin

17 Goedheer, J. C. (1965) Biochim. Biophys. Acta 102, 75-89

18 Boardman, N. K. (1970) Annu. Rev. Plant Physiol. 21, 115-140

19 Jennings, R. C. and Forti, G. (1974) Plant Sci. Lett. 3, 25-33

20 Duysens, L. N. M. (1964) Prog. Biophys. Mol. Biol. 14, 1-104

21 Marsho, T. V. and Kok, B. (1974) Biochim. Biophys. Acta 333, 353-365 